\title{
A Novel Cyclophane Compound, CPPy, Facilitates NGF-Induced TrkA Signal Transduction and Induces Cell Differentiation in Neuroblastoma
}

\author{
Yusuke Yamaguchi,${ }^{a}$ Keiichi Tabata, ${ }^{a}$ Satoru Asami, ${ }^{a}$ Muneharu Miyake, ${ }^{b}$ and Takashi Suzuki ${ }^{*}, a, c$ \\ ${ }^{a}$ Clinical Pharmacy, ${ }^{b}$ Medicinal Chemistry, College of Pharmacy, Nihon University; 7-7-1 Narashinodai, Funabashi, \\ Chiba 274-8555, Japan: and ${ }^{c}$ Department of Pediatrics, School of Medicine, Nihon University; 30-1 Oyaguchikami- \\ machi, Itabashi-ku, Tokyo 173-8610, Japan. \\ Received November 16, 2006; accepted January 4, 2007; published online January 15, 2007
}

\begin{abstract}
Neuroblastoma (NB) often causes spontaneously regression, and can mature to ganglioneuroma. The form with the most favorable prognosis expresses high levels of TrkA, a high-affinity receptor for nerve growth factor (NGF), whereas advanced NB and associated cell lines have abnormalities in the NGF/TrkA signaling pathway. A novel cyclophane, cyclophane pyridine (CPPy), was designed to conserve the tyrosine phosphorylation of TrkA, thereby enhancing NGF/TrkA signal transduction. We investigated whether this compound improved NGF-induced tyrosine phosphorylation of the Y490 domain of TrkA and conserved the expression of an early gene (cfos) in human NB cell lines (IMR-32 and NB-39). As determined by Western blotting, TrkA (Y490) phosphorylation was enhanced by the combination of CPPy $\left(10^{-8} \mathrm{M}\right)$ and NGF $(100 \mathrm{ng} / \mathrm{ml})$ compared with NGF alone. CPPy also conserved NGF-induced c-fos mRNA expression. Moreover, CPPy induced the morphological differentiation of NB cells, leading to expression of the neuronal marker gene $G A P-43$. These data suggest that CPPy can induce the differentiation of NB cell lines by facilitating NGF-induced TrkA/Ras/MAPK signal transduction, and may therefore be an effective therapeutic agent for NB.
\end{abstract}

Key words cyclophane; neuroblastoma; nerve growth factor (NGF); TrkA; differentiation

Neuroblastoma (NB), a common solid tumor of childhood, is thought to originate from sympathoadrenal progenitor cells in the neural crest. ${ }^{1)} \mathrm{NB}$ has been shown to be more often spontaneously regression than any other tumor, but to mature to differentiated ganglioneuroma., ${ }^{2,3}$ Despite intensive chemotherapy, NB patients with advanced-stage disease still have an extremely poor prognosis. ${ }^{4}$ Therapeutic trials aimed at arresting cell growth and inducing differentiation using chemical and biological agents (e.g., 13-cis retinoic acid) have been attempted to improve the prognosis. ${ }^{5}$ Previous studies have revealed that the growth, differentiation and survival of neural crest-derived cells are potently regulated by neurotrophins and their receptors. The neurotrophin family includes nerve growth factor (NGF), brain-derived neurotrophic factor (BDNF), neurotrophin-3 (NT-3), neurotrophin-4/5 (NT-4/5), and neurotrophin-6. ${ }^{6,7)}$ NGF is a targetderived neurotrophin that is identifiable in the early stages of NB. ${ }^{8)}$ It binds to a high-affinity NGF receptor, TrkA, and causes the differentiation for some neural cells. ${ }^{9)}$ It might therefore play an important role in the regression or differentiation of NB in vivo. There is accumulating evidence that the favorable (i.e. differentiated) form of NB strongly expresses trk $\mathrm{A}$, whereas trk $\mathrm{A}$ expression is significantly reduced in advanced NB or NB with $M Y C N$ gene amplification. ${ }^{10-12)}$ The addition of NGF to a primary culture of NB cells that expressed high levels of trkA resulted in neuronal differentiation, whereas most NB-derived cell lines did not respond to NGF treatment due to defects in their NGF/TrkA signaling pathway. ${ }^{13,14)}$ Hence, loss of function in the NGF/ TrkA signaling pathway probably contributes to the oncogenesis of NB. After binding to TrkA, NGF rapidly activates the tyrosine kinase activity of this receptor; autophosphorylation of the tyrosine residues within the intracellular signaling domain (Y490, Y670, Y674, Y675 and Y785) of TrkA then causes the signals to be transferred to multiple downstream effector proteins. ${ }^{15)}$ Pathways thought to be involved in NGF- mediated signal transduction include the Ras/Raf/MAP kinase, phospholipase C (PLC), protein kinase A (PKA), c-Jun $\mathrm{N}$-terminal kinase (JNK) and protein kinase $\mathrm{C}$ (PKC) pathways. ${ }^{15-17)}$ Phosphorylation of the Y490 domain of TrkA is required for Shc association and subsequent activation of the Ras/Raf/MAP kinase signaling pathway, which is very important for the NGF-mediated differentiation of NB cells. ${ }^{18)}$ These early signaling events lead to immediate and early gene expression (i.e., c-fos, Egr-1 $)^{19-21)}$ as well as to the induction of late response genes, which are responsible for the growth, differentiation and survival of neural cells.

With these factors in mind, we designed and synthesized a novel compound, CPPy, which acts as a conserver of tyrosine phosphorylation and facilitates NGF-induced TrkA signal transduction. In the present study, we investigated its usefulness in inducing the differentiation of NB cell lines. We here describe the in vitro activity of CPPy in phosphorylating TrkA (Y490), the induction of immediate and early genes, and cell differentiation.

\section{MATERIALS AND METHODES}

Cell Lines and Culture Two NB cell lines (IMR-32 and NB-39) were examined. The cell lines were cultured in RPMI 1640 with penicillin $(100 \mathrm{U} / \mathrm{ml})$, streptomycin $(0.1$ $\mathrm{mg} / \mathrm{ml})$, sodium bicarbonate $(2 \mathrm{mg} / \mathrm{ml})$ and heat-inactivated fetal bovine serum (FBS; $10 \%$ ) at $37^{\circ} \mathrm{C}$ under a $5 \% \mathrm{CO}_{2}$ atmosphere. The medium was changed every 2 to $4 \mathrm{~d}$.

Materials CPPy (Fig. 1) was dissolved in distilled water and filtered on a $0.22 \mu \mathrm{m}$ filter. NGF 7S (Roche Diagnostics, Mannheim, Germany) was dissolved in $0.75 \%$ bovine serum albumin in phosphate-buffered saline and stored at $-20^{\circ} \mathrm{C}$.

Western Blotting Cells $\left(5 \times 10^{6}\right.$ cells/60-mm dish) were treated with CPPy $\left(10^{-8} \mathrm{M}\right)$ for $7 \mathrm{~h}$, then stimulated with NGF $(100 \mathrm{ng} / \mathrm{ml})$ at $37^{\circ} \mathrm{C}$ for $0-30 \mathrm{~min}$. At the end of the incubation period, the cells were harvested into Tris-buffered saline 


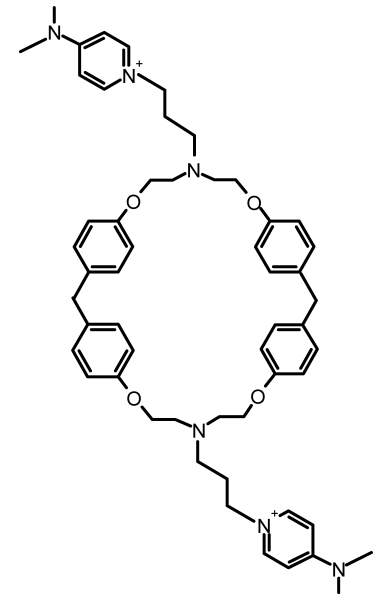

Fig. 1. Chemical Structure of CPPy (Molecular Weight 936)

(TBS; $20 \mathrm{~mm}$ Tris- $\mathrm{HCl}$ [pH 7.6], $137 \mathrm{~mm} \mathrm{NaCl).} \mathrm{After} \mathrm{cen-}$ trifugation for $10 \mathrm{~min}$ at $5000 \mathrm{rpm}$, the pellets were lysed in $250 \mu$ of sample buffer (1\% Nonidet P-40, $20 \mathrm{~mm}$ Tris [pH 8.0 ], $137 \mathrm{~mm} \mathrm{NaCl}, 10 \%$ glycerol, $1 \mathrm{~mm}$ phenylmethylsulfonylfluoride, $1 \mathrm{~mm}$ dithiothreitol) containing Protease Inhibitor Cocktail (Sigma, St. Louis, MO, U.S.A.) and Phosphatase Inhibitor Cocktail (Sigma), then sonicated. For sodium dodecylsulfate-polyacrylamide gel electrophoresis, $20 \mu \mathrm{g}$ of protein per lane was run on a $7.5 \%$ gel and blotted onto a polyvinylidine difluoride membrane (Amersham Biosciences, Buckinghamshire, U.K.). The membranes were soaked in blocking buffer ( $20 \mathrm{~mm}$ Tris- $\mathrm{HCl}$ [pH 7.6], $137 \mathrm{~mm}$ $\mathrm{NaCl}, 5 \%$ skim milk) for $1 \mathrm{~h}$ at room temperature, then treated with anti-phosphorylated-TrkA antibody (diluted 1 : 1000; Calbiochem-Novabiochem, San Diego, CA, U.S.A.) overnight at $4{ }^{\circ} \mathrm{C}$. The membranes were washed repeatedly with TBS containing $0.1 \%$ Tween 20 , then treated with a horseradish peroxidase-conjugated secondary antibody (diluted $1: 20000$ ) for $1 \mathrm{~h}$. The targeted protein was visualized using an electrochemiluminescence kit (ECL system; Amersham Biosciences). The optical density of the blots was measured using National Institutes of Health image $\mathrm{J}$ software. The blots were stripped from the gel by incubating them in stripping buffer $(62.5 \mathrm{~mm}$ Tris- $\mathrm{HCl}$ [pH 6.7], $2 \%$ SDS, $100 \mathrm{~mm} \beta$-mercaptoethanol) for $30 \mathrm{~min}$ at $50^{\circ} \mathrm{C}$, followed by two washes and reblocking. The membrane was also analyzed by the methods described above after reprobing with pan-TrkA antibody (diluted 1:1000; Santa Cruz Biotechnology, Santa Cruz, CA, U.S.A.). Activation of TrkA (Y490) was determined by comparing the density of the band containing phosphorylated TrkA (Y490) with that of the band containing pan-TrkA from the same sample.

Reverse Transcription Polymerase Chain Reaction (RTPCR) Cells $\left(5 \times 10^{6}\right.$ cells $/ 60$-mm dish $)$ were treated with CPPy $\left(10^{-8} \mathrm{M}\right)$ for $7 \mathrm{~h}$, then stimulated with NGF $(100 \mathrm{ng} / \mathrm{ml})$ at $37^{\circ} \mathrm{C}$ for $0-12 \mathrm{~h}$. Total RNA was extracted using TRIzol reagent (Invitrogen, Carlsbad, CA, U.S.A.) and quantified by UV absorbance spectroscopy. RT-PCR was performed using an RNA PCR kit (AMV Ver. 2.1; TaKaRa, Shiga, Japan). Total RNA ( $250 \mathrm{ng}$ ) was reverse-transcribed using oligo-dT. Sequential incubation was carried out at $30^{\circ} \mathrm{C}$ for $10 \mathrm{~min}$, $45^{\circ} \mathrm{C}$ for $60 \mathrm{~min}$ and $99^{\circ} \mathrm{C}$ for $5 \mathrm{~min}$, with a final holding phase at $4{ }^{\circ} \mathrm{C}$. PCR amplification was carried out with $0.2 \mu \mathrm{M}$ of the following primers: c-fos forward, 5 '-CCCTCAGTGGAACCTGTCAA-3'; c-fos reverse, 5'-GATGATGCTGGGAACAGGAA-3'; GAP-43 forward 5'-CTGTCCTTTCCCACCCACTA-3'; GAP-43 reverse, 5'-GAACGGAACATTGCACACAC-3'; $\beta$-actin forward, 5'-CAAGAGATGGCCACGGCTGCT-3'; $\beta$-actin reverse, $5^{\prime}$-TCCTTCTGCATCCTGTCGGCA- $3^{\prime}$. The GAP-43 cDNA PCR primers were used as described previously. ${ }^{22)}$ The PCR conditions for $\mathrm{c}-$ fos and $\beta$ actin amplification were: 35 cycles of template DNA denaturing at $94^{\circ} \mathrm{C}$ for $15 \mathrm{~s}$, annealing and extension at $68^{\circ} \mathrm{C}$ for $30 \mathrm{~s}$ and holding at $4^{\circ} \mathrm{C}$. For $G A P-43$, the conditions were: 1 cycle of template DNA denaturing at $95^{\circ} \mathrm{C}$ for $1 \mathrm{~min}$ followed by 30 cycles of denaturing at $95^{\circ} \mathrm{C}$ for $1 \mathrm{~min}$, annealing at $60^{\circ} \mathrm{C}$ for $1 \mathrm{~min}$ and extension at $72^{\circ} \mathrm{C}$ for $1 \mathrm{~min}$. After the last cycle, extension was continued for an additional 10 min at $72{ }^{\circ} \mathrm{C}$, followed by holding at $4{ }^{\circ} \mathrm{C}$. A bioanalyzer (Agilent Technologies, Waldbronn, Germany) was used to quantify the expression of the PCR products. The expression of c- $f o s$ and $G A P-43$ was determined by normalization relative to $\beta$-actin expression. All quantitative RT-PCR experiments were performed in triplicate.

Analysis of Cell Morphology For the cell differentiation studies, NB-39 cells were seeded at $1 \times 10^{5}$ cells $/ 60-\mathrm{mm}$ fibronectin-coated dish (Beckton Dickinson, Bedford, MA, U.S.A.) in RPMI 1640 containing 1\% FBS, treated with CPPy $\left(10^{-8} \mathrm{M}\right)$ for $7 \mathrm{~h}$, then stimulated with NGF (100 ng/ $\mathrm{ml}$ ). The cultures from at least three different regions were observed under a phase-contrast microscope and photographed at $96 \mathrm{~h}$ after NGF treatment. The percentage of differentiated cells was then counted. The degree of differentiation was graded according to four morphological features: 'differentiated' (neurites or drawing-out of the soma present), 'elongated' (possessing neurites longer than the diameter of the soma), 'branched' (possessing branches of neurites) and 'multiple' (multiple neurites issuing from the soma).

Cell Viability Testing by Trypan Blue Dye Exclusion IMR-32 cells $\left(3.5 \times 10^{6}\right.$ cells $/ 60$-mm dish $)$ were treated with CPPy $\left(10^{-8} \mathrm{M}\right)$ for $7 \mathrm{~h}$, then stimulated with NGF at $37^{\circ} \mathrm{C}$ for $0-48 \mathrm{~h}$. After incubation, the cells were trypsinized and an equal volume of $1.0 \%$ aqueous trypan blue dye solution was added to the cell suspension. The percentage of viable cells was counted in triplicate under a phase-contrast microscope.

Statistical Analysis Quantitive TrkA phosphorylation was compared between cells treated with NGF alone and cells treated with a combination of CPPy and NGF using paired $t$-tests. Quantitive results for c-fos mRNA and GAP-43 mRNA expression, morphological differentiation and cell viability tests were analyzed using two-way ANOVA. All analyses were performed using GraphPad Prism 3 (GraphPad, San Diego, CA, U.S.A.).

\section{RESULTS}

CPPy Facilitates NGF-Induced Tyrosine Phosphorylation of TrkA (Y490) We investigated the maximum functional CPPy concentration and most appropriate timing of application for facilitating the activation of signal transduction based on c-fos mRNA expression using competitive RTPCR in IMR-32 cells. The strongest expression of c-fos mRNA was observed when the cells were treated with CPPy $\left(10^{-8} \mathrm{M}\right)$ for $7 \mathrm{~h}$ then stimulated with NGF $(100 \mathrm{ng} / \mathrm{ml})$ for $1 \mathrm{~h}$ 
A

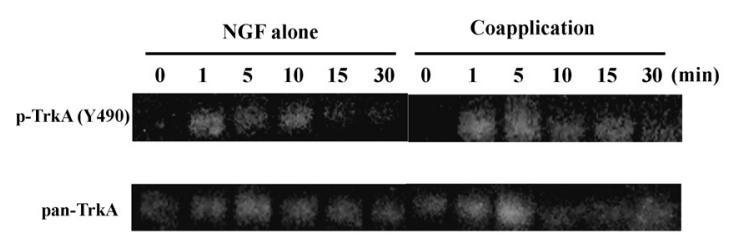

B

IMR-32

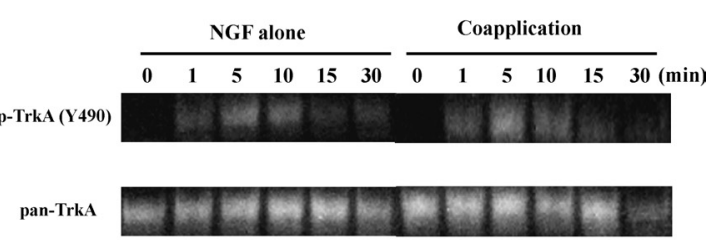

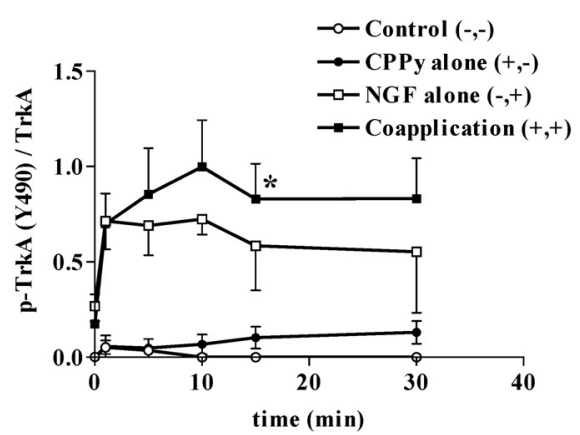

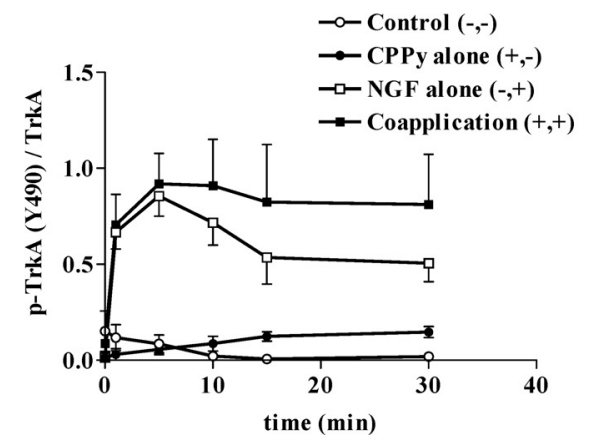

Fig. 2. Regulation of the Phosphorylation of TrkA (Y490) by CPPy and NGF

Western blots of phospho-TrkA (Y490) and pan-TrkA and quantitative analysis of TrkA phosphorylation in NB-39 (A) and IMR-32 (B) cells. Activated TrkA was calculated as the ratio of phosphorylated TrkA (p-TrkA) to pan-TrkA protein (TrkA). Cells were treated with CPPy $\left(10^{-8} \mathrm{M}\right)$ for $7 \mathrm{~h}$, then stimulated with NGF $(100 \mathrm{ng} / \mathrm{ml})$ for the time indicated. Control groups received vehicle alone $(-,-)$, CPPy alone $(+,-)$ or NGF alone $(-,+)$. The coapplication group $(+,+)$ received both CPPy and NGF. The results are expressed as the mean \pm S.E.M. from three independent experiments. $* p<0.05 v$ s. NGF alone (paired $t$-test).

A

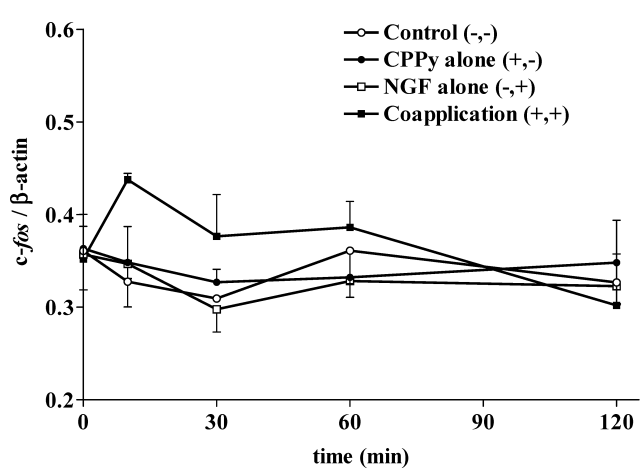

B IMR-32

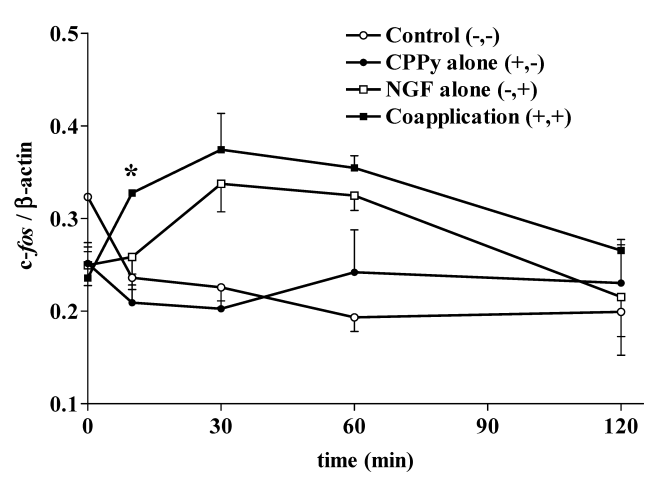

Fig. 3. CPPy Enhances NGF-Induced Expression of c-fos mRNA

Cells were treated with CPPy $\left(10^{-8} \mathrm{M}\right)$ for $7 \mathrm{~h}$, then stimulated with NGF $(100 \mathrm{ng} / \mathrm{ml})$ for the time indicated. Cells were treated with vehicle alone (control), CPPy alone, NGF alone or a combination of CPPy and NGF (coapplication). The expression of c-fos mRNA was detected using RT-PCR and expressed as a ratio relative to levels of the housekeeping gene ( $\beta$-actin). (A) NB-39 cells, (B) IMR-32 cells. The results are expressed as the mean \pm S.E.M. from three independent experiments. $* p<0.05$, interaction between CPPy and NGF as compared by two-way ANOVA.

(data not shown). Hence, these conditions were used for all the following experiments. To determine whether CPPy could potentiate TrkA phosphorylation, the expression levels of phosphorylated TrkA (Y490) and pan-TrkA were analyzed by Western blotting. Two NB cell lines (IMR-32 and NB-39) were treated with CPPy and/or NGF $(100 \mathrm{ng} / \mathrm{ml})$. As shown in Fig. 2A, treatment with NGF resulted in rapid phosphorylation of TrkA (Y490), reaching a maximum at $10 \mathrm{~min}$. However, phosphorylated TrkA immunoreactivity was no longer detectable at $60 \mathrm{~min}$ after NGF treatment (data not shown). When NB-39 cells were treated with a combination of CPPy and NGF, the relative expression of phospho-TrkA (Y490) was significantly increased compared with NGF alone and this increase was maintained at $30 \mathrm{~min}$ after stimulation. Similar results were obtained in IMR-32 cells (Fig. 2B).
CPPy itself had no effect on the phosphorylation of TrkA (Y490), a situation similar to that seen in control cells (without CPPy or NGF). No changes in the amounts of pan-TrkA were detected in IMR-32 and NB-39 cells treated with CPPy and/or NGF.

Immediate Early Gene Induction To determine whether CPPy can increase early gene expression in the nucleus, we used RT-PCR analysis to detect the presence of cfos. Compared to cells treated with NGF alone, IMR-32 and NB-39 cells treated with a combination of CPPy and NGF showed transient but marked increases in c-fos mRNA at 10 min or 30 min after NGF stimulation (the peak time for every reaction; Figs. 3A, B). Expression of c-fos mRNA had generally returned almost to its basal level by $2 \mathrm{~h}$; however, it tended to remain elevated in IMR-32 cells treated with a 
A

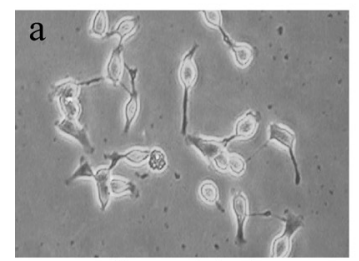

Control (-,-)

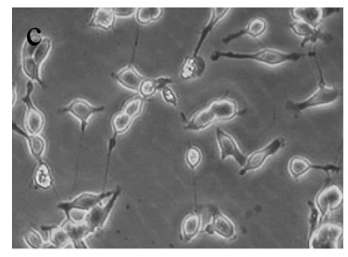

NGF alone $(-,+)$

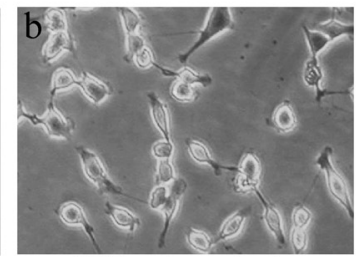

CPPy alone $(+,-)$

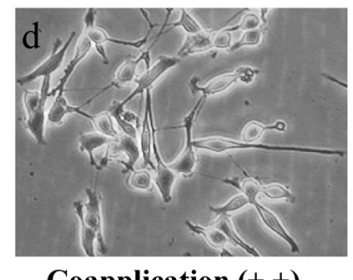

Coapplication $(+,+)$

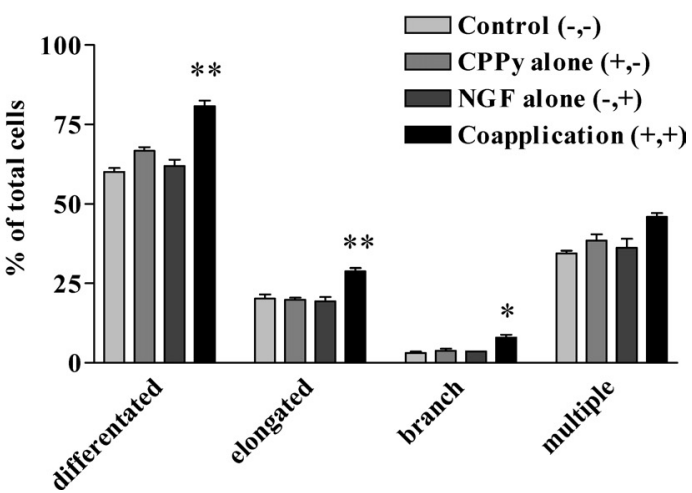

Fig. 4. CPPy Combined with NGF Induces Morphological Differentiation in NB-39 Cells

NB-39 cells were treated with CPPy $\left(10^{-8} \mathrm{M}\right)$ for $7 \mathrm{~h}$, then with NGF $(100 \mathrm{ng} / \mathrm{ml})$. Phase-contrast micrographs of NB-39 cells grown in medium alone (A-a) or medium supplemented with CPPy alone (A-b), NGF alone (A-c) or CPPy+NGF (A-d) were assessed at $96 \mathrm{~h}$ after NGF treatment. The degree of differentiation was scored as described in Material and Methods (B). The results are expressed as the mean \pm S.E.M. from three or four independent experiments. $* p<0.05$, $* * p<0.01$, interaction between CPPy and NGF as determined by two-way ANOVA.

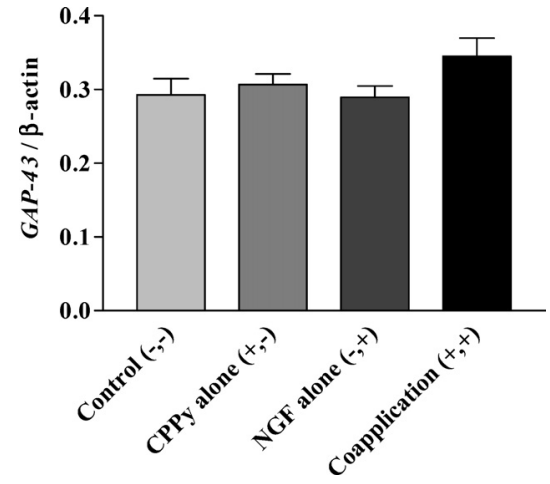

Fig. 5. CPPy Combined with NGF Enhances Expression of the Neuronal Differentiation Marker Gene GAP-43 in NB-39 Cells

Cells were treated with vehicle alone (control), CPPy alone, NGF alone or a combination of CPPy and NGF (coapplication). The expression of GAP-43 mRNA was detected using RT-PCR and expressed as a ratio relative to levels of the housekeeping gene $(\beta$-actin). The results are expressed as the mean \pm S.E.M. from three independent experiments.

combination of CPPy and NGF compared to NGF alone. CPPy itself had no effect on the expression of c-fos mRNA, similar to the situation seen in control cells.

Analysis of Cell Differentiation We addressed the question of whether CPPy facilitates NGF-induced differentiation. This was evaluated both morphologically, by estimating the percentage of differentiated cells as described above, and biochemically, by analyzing the expression level of GAP-43 mRNA, which is critical to the establishment of axonal outgrowth during the initiation and remodeling of neural connections. ${ }^{23)}$ As shown in Fig. 4A, neither NGF nor CPPy produced any morphological effects (Fig. 4A, panel a). However, extensive outgrowth of neurites that made cell-to-cell connections was observed on coapplication of CPPy and NGF (Fig. 4A, panel d). Two-way ANOVA detected a significant interaction of NGF and CPPy in the differentiated, elongated and branched cell groups (Fig. 4B). GAP-43 mRNA expression was detected at $24 \mathrm{~h}$ after NGF treatment by RT-

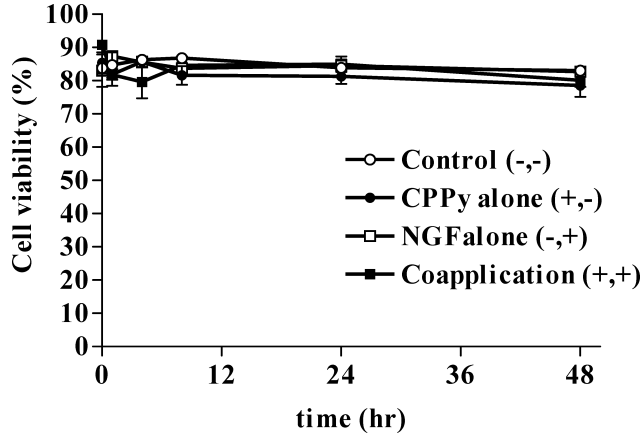

Fig. 6. Effects of CPPy and NGF on Cell Viability

IMR-32 cells were treated with vehicle alone (control), CPPy alone, NGF alone or a combination of CPPy and NGF over a 48 -h period. Cell viability was analyzed by trypan blue exclusion. The results are expressed as the mean \pm S.E.M. from three independent experiments.

PCR. The expression level of GAP-43 mRNA tended to increase in response to coapplication of CPPy and NGF (Fig. 5) and these increases paralleled the observed morphological changes.

Cell Viability To determine any cytotoxic effects of CPPy $\left(10^{-8} \mathrm{M}\right)$, we measured cell viability by the $0.5 \%$ trypan blue dye exclusion method. Neither CPPy alone nor CPPy combined with NGF affected cell viability from 0 to $48 \mathrm{~h}$ after NGF treatment (Fig. 6). No cell toxicity was observed at a CPPy dose of $10^{-8} \mathrm{M}$.

\section{DISCUSSION}

We previously reported that cyclophanes act as host compounds that trap organic 'guests' such as 4-nitrophenyl phosphate (NPP) due to the hydrophobicity of their aromatic ring group as well as binding to the phosphate group through an electrostatic interaction. ${ }^{24,25)}$ We have recently designed and synthesized a novel water-soluble cyclophane (CPPy) that bears 4-dimethylaminopyridinium groups on the alkyl-chain 
branches of a diphenylmethane skeleton (Fig. 1). We confirmed that CPPy has similar organic guest-trapping activity to NPP (unpublished data). The results of the present study demonstrate that CPPy facilitates NGF-induced TrkA/Ras/ MAPK signal transduction and cell differentiation in NB cell lines. NGF has been shown to induce neurite extension in TrkA-positive NB cell lines through activation of the Ras/MAP kinase cascade. ${ }^{9,18)}$ Previous studies have also reported that defects in the NGF/TrkA pathway can be responsible for the initiation or maintenance of the undifferentiated form of NB. ${ }^{13,14)}$

We used Western blot analysis in two NB cell lines to examine the effect of CPPy on the initial event of NGF/TrkA signal transduction. Autophosphorylation of TrkA (Y490) occurred rapidly upon exposure to NGF; peak phosphorylating activity was observed approximately $5 \mathrm{~min}$ after NGF stimulation, in agreement with findings in $\mathrm{PC} 12$ cells. $\left.{ }^{26}\right)$ Compared to NGF alone, the relative expression of phosphoTrkA (Y490) was increased by a combination of CPPy and NGF in both IMR-32 and NB-39 cells. It appears that CPPy facilitates the phosphorylation reaction in the tyrosine residues of TrkA and prevents phosphorylated TrkA (Y490) from being hydrolyzed by protein tyrosine phosphatase. As CPPy alone did not affect the phosphorylation of TrkA (Y490), it appears that it functions by enhancing NGF/TrkA signal transduction. Previous studies have showed that tetanus toxin (TeTx) also binds to the TrkA receptor and stimulates PLC $\gamma$-1 tyrosine-phosphorylation, as well as causing TrkA activation. ${ }^{27)}$ Moreover, FK506 potentiates NGF-induced neurite outgrowth via the Ras/Raf/MAP kinase pathway. ${ }^{28)}$ However, neither TeTx nor FK506 directly enhance NGF-induced phosphorylation of TrkA in NB cell lines, unlike CPPy, which seems to affect the pathway directly. The NGF-induced phosphorylation of TrkA (Y490) points to a parallel interaction between Shc proteins and TrkA, an important event in neuronal differentiation. ${ }^{29)}$ Shc adaptor proteins are the first link in a pathway that results in Ras/MAPK activation. ${ }^{30)}$ In this study, increases in c-fos mRNA were observed in NB cell lines after NGF treatment. These increases may be a consequence MAPK pathway activation because growth-factor-induced c-fos expression is mediated by transcription factors such as Elk-1 and SAP-1, which are targets of Ras/MAPK-mediated phosphorylation. ${ }^{16)}$ Furthermore, CPPy may have acted synergistically with NGF to facilitate c-fos transcription because the increased phosphorylation of TrkA (Y490) caused by CPPy could have had an effect on early transcriptional gene production in the nucleus via the Ras/MAPK pathway.

It has been reported that the differentiation of NB caused by NGF, retinoids or 12-O-tetradecanoylphorbol-13-acetate is accompanied by upregulation of c-fos. ${ }^{19,31,32)}$ In addition to increasing c-fos transcript levels, CPPy combined with NGF induced neurite outgrowth in NB-39 cells. The expression level of GAP-43 mRNA tended to be elevated by combined CPPy and NGF, and this elevation paralleled to the degree of morphological differentiation. GAP-43 has an ets site in its promoter sequence, ${ }^{33)}$ which can bind to transcriptional factors of the ets family (e.g., Elk-1). These genetic findings are in agreement with our results indicating activation of the Ras/MAPK cascade by CPPy and upregulation of GAP-43. These data suggest that CPPy can induce neuronal differenti- ation by facilitating NGF/TrkA signal transduction.

In the present study, NGF alone did not induce morphological differentiation and expression of GAP-43 mRNA in NB-39 cells. Similarly, Sugimoto et al. reported that NGF treatment did not induce c-fos mRNA or morphological neurite outgrowth in human NB-derived MP-N-TS cells expressing TrkB receptors in addition to TrkA. ${ }^{34)}$ As we also found that TrkB mRNA was expressed in NB-39 cells when analyzed by RT-PCR (data not shown), the above results might also be applicable to NB-39 cells.

In summary, it seems likely that at a concentration too low to produce cytotoxicity, CPPy could induce the differentiation of NB cell lines through activation of the NGF-induced TrkA/Ras/MAPK pathway. Furthermore, our results demonstrate that CPPy enhances NGF/TrkA signal transduction via a common growth factor signaling pathway, but has no neurotrophic properties in itself, suggesting that nonspecific stimulation of neurotrophin substrates would be reduced in vivo. It is possible that CPPy may target other tyrosine residues; however, further experiments are needed to confirm whether CPPy facilitates the tyrosine phosphorylation of other proteins (e.g., PLC $\gamma$-1, PI3-K). Nevertheless, its effect on TrkA (Y490) indicates that CPPy may be a useful therapeutic agent with little toxicity for the treatment of NB.

Acknowledgments We would like to thank Dr. Toshimitsu Suzuki (Fukushima Medical University School of Medicine) for providing the NB-39 cell line. This work was supported by "Academic Frontier" Project for Private Universities: matching fund subsidy from MEXT (Ministry of Education, Culture, Sports, Science and Technology) 20022006.

\section{REFERENCES}

1) Bolande R. P., Hum. Pathol., 5, 409-429 (1974).

2) Evans A. E., Gerson J., Schnaufer L., Natl. Cancer Inst. Monogr., 44, 49-54 (1976).

3) Aterman K., Schueller E. F., Am. J. Dis. Child., 120, 217-222 (1970).

4) Weinstein J. L., Katzenstein H. M., Cohn S. L., Oncologist, 8, 278 292 (2003).

5) Reynolds C. P., Matthay K. K., Villablanca J. G., Maurer B. J., Cancer Lett., 197, 185-192 (2003).

6) Chao M. V., Neuron, 9, 583-593 (1992).

7) Snider W. D., Cell, 77, 627-638 (1994).

8) Levi-Montalcini R., Science, 237, 1154-1162 (1987).

9) Klein R., Jing S. Q., Nanduri V., O'Rourke E., Barbacid M., Cell, 65, 189-197 (1991).

10) Nakagawara A., Arima M., Azar C. G., Scavarda N. J., Brodeur G. M., Cancer Res., 52, $1364-1368$ (1992).

11) Nakagawara A., Arima-Nakagawara M., Scararda N. J., Azar C. G., Cantor A. B., Brodeur G. M., N. Engl. J. Med., 328, 847-854 (1993).

12) Suzuki T., Bogenmann E., Shimada H., Stram D., Seeger R. C., J. Natl. Cancer Inst., 85, 377-384 (1993).

13) Azar C. G., Scararda N. J., Reynolds C. P., Brodeur G. M., Cell Growth Differ., 1, 421—428 (1990).

14) Nakagawara A., Brodeur G. M., Eur. J. Cancer, 33, 2050-2053 (1997).

15) Huang E. J., Reichardt L. F., Annu. Rev. Neurosci., 24, 677-736 (2001).

16) Segal R. A., Greenberg M. E., Annu. Rev. Neurosci., 19, 463-489 (1996).

17) Shields J. M., Pruitt K., McFall A., Shaub A., Der C. J., Trends Cell Biol., 10, 147-154 (2000).

18) Eggert A., Ikegaki N., Liu X., Chou T. T., Lee V. M., Trojanowski J. Q., Brodeur G. M., Oncogene, 19, 2043-2051 (2000). 
19) Bogenmann E., Peterson S., Maekawa K., Matsushima H., Oncogene, 17, 2367-2376 (1998).

20) Gomez N., Cohen P., Nature (London), 353, 170-173 (1991).

21) Thomas S. M., DeMarco M., D’Arcangelo G., Halegoua S., Brugge J. S., Cell, 68, 1031-1040 (1992).

22) Laifenfeld D., Klein E., Ben-Shachar D., J. Neurochem., 83, 10541064 (2002).

23) Yankner B. A., Benowitz L. I., Villa-Komaroff L., Neve R. L., Brain Res. Mol. Brain Res., 7, 39— 44 (1990).

24) Miyake M., Wilcox C. S., Heterocycles, 57, 515-522 (2002).

25) Metori K., Miyake M., Heterocycles, 60, 1441-1445 (2003).

26) Parran D. K., Barone S., Jr., Mundy W. R., Brain Res. Dev. Brain Res., 141, 71-81 (2003).

27) Gil C., Chaïb-Oukadour I., Pelliccioni P., Aguilera J., FEBS Lett., 481 , 177-182 (2000).

28) Price R. D., Yamaji T., Matsuoka N., Br. J. Pharmacol., 140, 825-829
(2003).

29) Loeb D. M., Tsao H., Cobb M. H., Greene L. A., Neuron, 9, 10531065 (1992).

30) Pelicci G., Lanfrancone L., Grignani F., McGlade J., Cavallo F., Forni G., Nicoletti I., Grignani F., Pawson T., Pelicci P. G., Cell, 70, 93-104 (1992).

31) Påhlman S., Hoehner J. C., Nånberg E., Hedberg F., Fagerstoröm S., Gestblom C., Johansson I., Larsson U., Lavenius E., Örtoft E., Söderholm H., Eur. J. Cancer, 31, 453-458 (1995).

32) Hovland A. R., Nahreini P., Andreatta C. P., Edwards-Prasad J., Prasad K. N., J. Neurosci. Res., 64, 302-310 (2001).

33) Örtoft E., Påhlman S., Andersson G., Parrow V., Betsholtz C., Hammerling U., Mol. Cell Neurosci., 4, 549-561 (1993).

34) Sugimoto T., Kuroda H., Horii Y., Moritake H., Tanaka T., Hattori S., Jpn. J. Cancer Res., 92, 152-160 (2001). 